\title{
A AFIRMAÇÃO DOS DIREITOS HUMANOS NUM CONTEXTO DE BIOPOLÍTICA: LÓGICA IMUNITÁRIA VERSUS LÓGICA DO COMUM
}

\author{
THE STATEMENT OF THE HUMAN RIGHTS IN A BIOPOLITICAL \\ CONTEXT: IMUNE LOGIC VERSUS COMMON LOGIC
}

José Roque Junges

\section{RESUMO}

0 artigo tem o objetivo de analisar as duas lógicas biopolíticas contrárias que atravessam a compreensão e a efetivação dos direitos humanos. Essa é uma tarefa central para a Bioética. Existe, por um lado, a lógica biopolítica negativa, que está a serviço da defesa dos direitos do indivíduo contra o coletivo, gerando dinâmicas imunitárias que isentam aos cidadãos dos encargos do comum. Essa lógica está presente no sistema jurídico moderno, entendido como sistema imunizador da sociedade. Por outro, tem-se presente a lógica biopolítica positiva, que assume os direitos humanos como dispositivos de potencialização da constituição do comum, como um caminho protetivo para sua concretização. Essa é a proposta da Bioética de proteção que defende que o Estado tem o dever de proteger populações e grupos vulneráveis por meio de políticas públicas. Um exemplo concreto desse atravessamento nos Direitos Humanos é o direito à saúde, quando se considera a judicialização da saúde. Essas duas lógicas biopolíticas aparecem na própria formulação da Declaração Universal de Bioética e Direitos Humanos que foi fruto de um consenso de concepções contrárias.

Palavras-chaves: Direitos Humanos. Imunidade jurídica. Comum.

\section{ABSTRACT}

This paper has the objective of analyzing two opposite biopolitical logics, which cross the understanding and the effectiveness of human rights. This is a core task for Bioethics. On one side, there is a negative biopolitical logic, 
which defends the rights of the individual against the collective, generating immune dynamics that are exempted from common responsibilities. This logic is present on the modern juridical system, which is understood as the society's immune system. On the other side, it is the positive biopolitical logic of human rights, which assumes human rights as a potential dispositive to the constitution of the common, as a protective way for their concretization. This is the proposal of the Bioethics of protection, which defends that the State must protect vulnerable groups and populations through public policies. A concrete example of this biopolitical crossing on human rights is the right of health when the judicialization of the health takes place. Both biopolitical logics are present in the formulation of the Universal Declaration of Bioethics and Human Rights, which were a consensual agreement of opposite positions.

Keywords: Human Rights. Juridical Immunity. Common.

\section{INTRODUÇÃO}

A bioética, que se impôs desde o seu surgimento, foi a que assumiu, como modelo, o paradigma principialista, fundado nos célebres três princípios: da autonomia, da beneficência e da justiça, tendo o primeiro destes princípios a primazia absoluta no contexto da cultura anglo-saxã. Esse modelo de bioética foi importado para outros contextos, sem a devida preocupação com sua enculturação, nem sua assunção crítica. A compreensão e a efetivação do que seja autonomia depende, essencialmente, de elementos culturais que, no caso brasileiro, são completamente diferentes de uma visão anglo-saxã.

Em situações de total assimetria e marginalização social, como é o caso do Brasil e dos países latino-americanos, não pode valer a perspectiva da isonomia e da igualdade de condições, deixando a concretização dos direitos e o acesso aos bens necessários a uma vida de qualidade à decisão autônoma dos cidadãos, como defende a mentalidade mediana dos cidadãos dos Estados Unidos, principalmente em tempos de Trump, demonstrada pela completa desconstrução dos pequenos avanços de acesso à saúde para populações carentes do assim chamado ObamaCare.

Por isso, em contextos de profunda desigualdade social, não pode valer a perspectiva principialista da autonomia para regular o acesso aos 
meios necessários para uma saúde de qualidade. Impõe-se outro paradigma de bioética para refletir e equacionar os problemas éticos ligados à saúde. É necessário partir da suscetibilidade ou da condição vulnerada da maioria das pessoas, instaurando o paradigma da vulneração que se diferencia do paradigma da pura isonomia, pautada pela autonomia. Para o paradigma da vulneração, a referência e o critério ético para avaliar as situações não são os princípios, mas os direitos humanos, cuja efetivação exige a intervenção prestativa do Estado através de políticas públicas para garantir a sua realização. Isso está expresso na Constituição Cidadã de 1988 no artigo 196: "A Saúde é um direito de todos e um dever do Estado", artigo que deu origem ao Sistema Único de Saúde do Brasil.

0 Direito à Saúde compreende tanto o acesso aos meios necessários para uma recuperação curativa em situações de enfermidade, quanto a criação de condições para a prevenção e a promoção da saúde, através de ações intersetoriais de melhoria dos ambientes e dos contextos de sociabilidade para minorar e superar os fatores que ocasionam agravos à saúde (FIGUEIREDO, 2007). Neste sentido, o Direito à Saúde é um direito que precisa conjugar a dimensão individual e coletiva da saúde. Portanto, ele não pode ser reduzido ao direito do consumidor, como pode sugerir a sempre maior judicialização da saúde, no caso de acesso a remédios raros, de recente comercialização e alto custo, compreendendo esse Direito como sendo um direito de consumir medicamentos e procedimentos que prometem saúde. Essa tendência pode levar a excessos e decisões desmedidas que são preocupantes (SARLET, SAAVEDRA, 2017). Por isso é necessário que os operadores do Direito estejam atentos à captura biopolítica que as grandes multinacionais farmacêuticas promovem do direito à saúde a partir de uma mentalidade consumista e individualista (JUNGES, 2009).

Esse fato aponta para a necessidade de situar a efetivação dos direitos, especialmente do Direito à saúde, no contexto atual de captura biopolítica da gestão da vida, promovida pelos grandes conglomerados biotecnológicos de saúde e de alimentação. Se antes os Estados exerciam o poder, hoje, são sempre mais os grandes oligopólios econômicos internacionais que marcam as cartas dos jogos políticos.

Até os tempos modernos, o eixo do poder era representado pela soberania sobre territórios, incluindo a população, fazendo com que toda 
a gestão política consistisse em ações de controle sobre esse território. Nesse espaço geográfico definido, o poder soberano fazia morrer ou deixava viver os habitantes dessas regiões. Nos tempos modernos esse foco vai mudar para a governança da população que pela sua gradativa magnitude surge como uma ameaça ao poder e, por isso, precisou ser governamentalizada a serviço dos interesses do sistema capitalista que estava sendo gestado. No começo, tratou-se em disciplinar os corpos como força de trabalho e, depois, foi acrescentada a governança da população que precisava ser monitorada para que se torne produtiva. 0 princípio, portanto, se inverte: o poder não se centra mais em fazer morrer, mas em fazer viver e deixar morrer. Assim, parece introduzir-se uma certa oposição entre o paradigma da soberania que tinha o poder de morte e o paradigma da biopolítica que investe em fazer viver (FOUCAULT, 1977). A população torna-se um elemento primordial do patrimônio da nação e, por isso, necessita ser qualificada através de normas para que possa ser conduzida ao seu fim, que é a produção da riqueza. Para essa condução biopolítica, o poder assumiu a forma da governamentalidade econômica, porque se tratava de uma gestão da vida como bem econômico. 0 exercício político sobre a vida da população (Biopolitica) é, antes de tudo, um exercício de governamentalidade econômica para a produção de riqueza. Foucault realiza, portanto, uma genealogia da forma de governamentalidade econômica e biopolítica do poder que vai, nos tempos modernos, desde o mercantilismo até o neoliberalismo (FOUCAULT, 2008).

Essa constatação pode sugerir que a biopolítica é o contexto para pensar criticamente os desafios éticos da bioética, pois pode fornecer um quadro interpretativo para entender as coordenadas socioculturais e político-econômicas da realidade atual que configuram os problemas que ela pretende enfrentar. Assim, não se pode analisar e equacionar esses problemas sem situá-los no contexto de gestão biopolítica da vida que caracteriza, fundamentalmente, tanto a economia como a política atuais.

0 artigo tem o objetivo de analisar esse contexto, refletindo sobre suas incidências na compreensão e efetivação dos direitos humanos. Primeiro, será feita uma análise da Biopolítica, tendo como base o pensamento de Roberto Esposito, Apontando os possíveis desvios na efetivação dos direitos humanos, decorrentes do paradigma jurídico 
imunitário que leva à isenção dos encargos do comum. Em seguida, é apresentado o paradigma da bioética de proteção, como interpretação e compreensão dos direitos, seguindo a perspectiva de Roland Schramm e Miguel Kottow, privilegiando a perspectiva do comum. Fica evidente que a afirmação dos direitos humanos é atravessada por duas lógicas biopolíticas: uma negativa, que transforma os direitos em instrumentos imunitários do indivíduo contra o comum, e outra positiva, que defende os direitos como dispositivos de potência para a constituição do comum.

\section{CONTEXTO BIOPOLÍTICO E O PARADIGMA JURÍDICO IMU- NITÁRIO}

Um autor que tentou levar adiante essa perspectiva genealógica de análise da governamentalidade biopolítica foi Roberto Esposito, tentando responder às aporias internas da análise de Foucault, entre a simultânea governança do poder de morte (soberania) e do poder de vida (biopolítica). Essas formas não se sucedem uma à outra, mas são simultâneas, segundo Esposito. Por isso, ele faz uma genealogia desse fenômeno, pelo qual a própria política da vida engendra medidas tanatológicas, porque a biopolítica é sempre atravessada pela política da soberania. Para analisar essa aparente contradição, Esposito propõe a imunologia biológica como paradigma social de explicação do funcionamento da sociedade moderna. A lógica imunitária da institucionalidade social, expressa no sistema jurídico, permite a simultânea presença da soberania (fazer morrer) e da biopolítica (fazer viver) na governamentalidade moderna. Ele parte da compreensão da estrutura de defesa do sistema imunitário biológico, que rejeita qualquer penetração de um ser estranho ao código genético daquele ser vivo. Na sociedade, quem exerce essa vigilância imunitária, é o direito que imuniza a sociedade e, respectivamente, seus cidadãos, contra as ameaças à sua integridade e às suas prerrogativas (ESPOSITO, 2005, 2006).

Para aprofundar a compreensão jurídica da lógica imunitária, Esposito faz uma análise linguística da própria palavra latina immunitas, base deste conceito. Trata-se de um vocábulo privativo de algo que se 
carece, no caso, o munus, isto é, o encargo, o dever, a obrigação. Imune, juridicamente, é aquele que está dispensado de um encargo em relação aos outros ou aquele que não deve nada a ninguém. Contudo, immunitas não é apenas uma dispensa, mas também um privilégio. Nesse sentido, é uma exceção à regra que os outros devem seguir, instaurando uma diferença em relação aos outros. Para entender isso é necessário à discussão o antônimo de immunitas que é a communitas. Para Esposito, "o verdadeiro antônimo de immunitas não é o munus ausente, mas a communitas daqueles que, ao contrário, se fazem seus portadores". (2005, p. 15). A imunidade é a condição particular daqueles indivíduos que se definem pelo "não comum", isto é, os que não tem encargos comuns relativos à communitas. Assim, a imunidade jurídica tem um sentido antissocial e anti-comunitário, porque interrompe a dinâmica social dos encargos comuns da comunidade. Portanto, o contraponto da dinâmica jurídica imunitária é a comunidade, que ela nega (ESPOSITO, 2005, 2007).

0 paradigma cultural moderno significou o surgimento do indivíduo independente e autônomo e o gradativo esvaziamento da pertença comunitária. Esse contexto permitiu a emergência da consciência dos direitos de cada sujeito singular, como direitos que podem ser exigidos do comum institucionalizado. Assim os direitos individuais foram assumindo o lugar dos deveres comuns como cimento da sociedade. Essa dinâmica cultural está na base do surgimento da lógica imunitária que caracteriza a sociedade moderna, institucionalizada no direito como sistema de salvaguarda da sociabilidade exposta a riscos e conflitos. O papel imunizador do sistema jurídico é garantir a sobrevivência da comunidade. Contudo, da mesma maneira como o sistema imunológico dos seres vivos se protege pela via negativa, criando anticorpos pela inoculação daquilo do qual quer defender-se, também a imunização do sistema jurídico tem um caráter negativo, pois não se defende de algo externo à sociedade, mas de algo interno que a constitui que é o cimento do comum. Nas palavras de Esposito:

O perigo, do qual o direito se propõe defender a vida em comum, é representado pela mesma relação, que a constitui como tal. Essa relação quebra os limites da identidade dos indivíduos e os expõe a uma alteração e, portanto, a um potencial conflito, com os outros. Ou também, unindo a seus 
membros num vínculo de necessária reciprocidade, tende a confundir os limites do que é próprio de cada um deles com o que é de todos e, portanto, de ninguém (ESPOSITO, 2005, p. 36).

Assim, o direito é o defensor daquilo que conecta, isto é, dos deveres comuns, tendo como referência os direitos de cada um. Aqui se encontra, segundo Esposito, a contradição fundamental do Direito: querer defender a sociedade dos conflitos sociais, inoculando-a com a desagregação, quando defende os indivíduos dos encargos comuns por estarem pautados nos direitos individuais de cada um. Assim o Direito conserva a sociedade, destituindo-a de seus fundamentos, que é o comum. Em outras palavras o Direito imuniza os indivíduos contra os outros membros da sociedade, porque seu fundamento é a defesa daquilo que é próprio e direito de cada um. Nesse sentido, a origem última do Direito, em sua lógica imunitária, é a defesa da propriedade (ESPOSITO 2005, 2007).

O Direito moderno é um Direito contratualista para a defesa dos direitos de cada um, focada fundamentalmente no indivíduo e não naquilo que é comum a eles. Por isso não existe, nas sociedades modernas, um Direito comunitário para defender aquilo que é comum e as relações comunais que cimentam a sociabilidade. 0 Direito, em última análise, protege os direitos individuais daqueles que fazem parte do contrato social pactuado para defender os interesses de cada um. Para Esposito, essa lógica imunitária explica a permanência da soberania e suas dinâmicas tanatológicas na governança biopolítica de promoção da vida (ESPOSITO, 2005).

Essa análise de Esposito ajuda a entender a possibilidade da captura biopolítica negativa dos direitos humanos pela lógica imunitária do Direito que se foca na defesa dos direitos do indivíduo contra as exigências do comum. Um exemplo dessa captura pode estar presente na atual judicialização do Direito à saúde (JUNGES, 2009). Mas, como Foucault, já havia alertado o poder, por estar sempre aliado ao saber, pode também assumir uma versão afirmativa de crítica e resistência ao biopoder, que possibilita agir contra a captura da vida e potenciá-la (FOUCAULT, 1999). Nessa perspectiva, os direitos humanos tornam-se dispositivos biopolíticos da afirmação da vida contra a morte. Entretanto, a potência 
de vida dos direitos só é possível, quando criadas as condições coletivas de sua efetivação. A realização dos direitos humanos não acontece contra o comum, pelo esvaziamento da sua institucionalização, mas pela sua potencialização. A proposta da bioética de proteção é um paradigma que assume essa perspectiva.

\section{A BIOÉTICA DE PROTEÇÃO E OS DIREITOS HUMANOS}

A Bioética de Proteção, proposta por Schramm e Kottow (2001), tem como foco os problemas de saúde pública, discutindo criticamente a aplicabilidade dos clássicos princípios da bioética e de outros princípios como a solidariedade e a responsabilidade, por tratar-se de uma relação assimétrica com pessoas vulneráveis. 0 único caminho adequado é uma ética da proteção.

Para explicitar o sentido da expressão os autores vão para a etimologia da própria palavra ética. Ethos, no grego antigo, significa guarida para os animais, refúgio e proteção para os seres humanos (SCHRAMM, KOTTOW, 2001). A raiz original da palavra contém o sentido de gruta e lar de proteção, e foi este sentido material que passou para o significado do conceito de ética que expressa atitudes protetivas. 0 mesmo se pode dizer do papel do Direito que também tem um significado de proteção, oferecido pelo grupo social de pertença.

Falando de refúgio e proteção, pode-se perguntar: proteger em relação a quê? A referência das atitudes de proteção são os indivíduos e os grupos vulnerados. A situação de vulneração de quem está ameaçado por riscos e perigos é que suscita ações de guarida e proteção. Por isso, a ética de proteção é o modelo correspondente e coerente com o paradigma da vulnerabilidade, melhor, da suscetibilidade a vulnerar-se e a ser vulnerado. 0 âmbito onde as pessoas mais podem vulnerar-se é a saúde, sendo o papel da saúde pública protege-las de riscos e agravos através de políticas públicas de saúde. Ações coletivas de proteção da saúde da população tornam-se imperativas para a função do Estado. Neste sentido, a bioética de proteção é o modelo apropriado para pensar e equacionar os desafios e os problemas éticos de saúde pública. Esse é o fundamento da proposta de bioética de proteção (KOTTOW, 2005). 
Em situações de vulneração de pessoas individuais, como crianças ou idosos, pode ser evocado o princípio da responsabilidade, porque se trata de seres com identificação pessoal singularizada. É o caso de relações familiares e de amizade, ou mesmo, de uma relação de médico-paciente. Ao contrário, quando se trata de um destinatário não identificável, como a população em geral, que é o foco de preocupação da saúde pública, não pode servir o princípio da responsabilidade, porque as ações públicas sanitaristas não são fruto de um requerimento interposto por algum paciente, mas de uma ação oferecida livre e coletivamente por um agente moral, obedecendo a um dever imperfeito, pautado por critérios científicos e políticos, decorrente de uma atitude moral. Portanto, as ações requeridas pela saúde pública não são deveres propriamente ditos. Trata-se de uma responsabilidade sem cobrança e obrigações definidas para com alguém com rosto concreto, não podendo, por isso, servir de princípio ético para as ações da saúde pública, porque o seu foco é a população em geral, um personagem não identificável. Por isso é necessário introduzir o princípio da proteção que não tem como referência uma relação pessoal "eu-tu", como acontece na responsabilidade, mas uma relação neutra, especificada pelo pronome "ele-eles" (SCHRAMM 2003).

A exigência de ações protetivas da saúde por parte de agentes públicos refere-se a grupos populacionais, cujos interesses individuais não são identificáveis nem os resultados dessas ações podem ser individualmente descritos, fazendo com que o critério dos direitos pessoais do liberalismo e as consequências do utilitarismo não podem servir de referenciais éticos para avaliar as ações protetivas (SCHRAMM, 2003).

Qual é, então, a referência ética para ações que tem, como foco, a preocupação protetiva da saúde e do bem-estar da população em situação de vulneração? A base para avaliar essas ações é a efetivação dos direitos humanos, proclamados para proteger grupos vulneráveis, não bastando a validação ética e jurídica dos direitos humanos na Constituição Federal de 1988. É necessária a institucionalização de medidas práticas que criem as condições jurídicas e políticas para a concretização dos direitos humanos. Isso acontece através de políticas públicas como ações protetivas do Estado para possibilitar a realização efetiva dos direitos, 
principalmente daqueles grupos mais vulneráveis no acesso aos bens que os direitos garantem (CHRISPINO, 2016).

A efetivação dos direitos humanos pode depender de ações ao nível micro, quando se tomam medidas particulares e concretas para amparar grupos e indivíduos em situação de fragilidade e/ou vulnerabilidade, que não dispõem das condições indispensáveis para ter acesso a determinado bem que faz parte do direito à saúde em determinados casos. Valem, como exemplo, as políticas públicas materno-infantis, do cuidado de pessoas portadoras do vírus do HIV ou acometidos por doenças crônicas etc. Trata-se, pois, de ações protetivas específicas curativas, recuperativas e preventivas que fazem parte de uma bioética de proteção stricto sensu. Pode-se falar, também, de uma bioética de proteção lato sensu, quando se refere a iniciativas macros de proteção que devem ser universalizáveis (SCHRAMM, 2006).

A bioética de proteção, em sentido lato, refere-se a macro políticas públicas sanitaristas, base sistêmica para que as políticas específicas e particulares possam ser efetivadas e está expressa na institucionalidade do Sistema Único de Saúde (SUS). As medidas organizacionais de proteção são universalizáveis porque criam as condições ambientais e sociopolíticas que garantem, para todos, uma vida digna e com qualidade. Essa bioética da saúde pública tem como escopo a defesa da proteção sistêmica do direito à saúde, garantida pelo SUS, e como referenciais éticos, seus princípios da universalidade, equidade e integralidade, como valores que inspiram a realização do direito à saúde. Estamos falando de uma bioética de proteção lato sensu (SCHRAMM, 2006).

\section{LÓGICA IMUNITÁRIA VERSUS LÓGICA DO COMUM NA APLICAÇÃO DOS DIREITOS HUMANOS}

Tendo presente o paradigma jurídico imunitário e a bioética de proteção, explicitados nos pontos anteriores, pode-se afirmar que a concretização dos direitos humanos é permeada por duas lógicas biopolíticas: a lógica negativa imunitária, que isenta dos encargos do comum, criando dispensas e privilégios, baseado nos direitos, e a lógica 
positiva do comum, que possibilita a potência da vida que está na base dos direitos humanos.

A lógica imunitária baseia-se no paradigma moderno da autonomia do indivíduo e na sua correspondente categoria de pessoa que serviu de fundamentação para os direitos humanos. A Declaração Universal dos Direitos Humanos de 1948 quis fazer frente à brecha entre o ser humano e o cidadão que baseava a proclamação restritiva anterior de 1789, concedendo direitos somente aos cidadãos da elite, mas excluindo a maioria da população. Por outro lado, desejava-se superar a gradativa deriva biológica da concepção do ser humano, dessubjetivado, despersonalizado e reduzido a processos biológicos, cuja visão redutiva justificou os horrores do nazismo. Por isso, a Declaração de 1948 tomou a opção de partir da reinvindicação incondicionada da pessoa humana que se definia plenamente inclusiva para superar as ideias restritivas e redutivas do humano. A categoria de pessoa incluía a todos seres humanos e impedia sua redução ao substrato biológico, porque possuía um excedente de caráter espiritual que não se identificava com o biológico. 0 formulador dessa concepção, que serviu de fundamentação para os direitos humanos, foi o filósofo cristão Jacques Maritain (1967). Essa visão integral foi, contudo, uma exceção no ascendente processo de biologização da antropologia que continua até os nossos dias. A fragilidade dessa visão para impedir a deriva biopolítica está na compreensão da própria categoria de pessoa (ESPOSITO, 2009).

A proposta de Maritain significava uma volta à categoria substancial de pessoa para opor-se à redução do humano à sua componente corporal biológica, considerada meio de inserção do indivíduo no corpo racial espécie, que estava na base da biopolítica nazista. Para essa volta, era necessário distinguir e distanciar o componente espiritual, racional, do ser humano do seu puro dado físico corporal. Para Maritain, o ser humano, como pessoa, identifica-se com sua componente espiritual que goza de soberania para comandar seu substrato biológico, unificando as duas partes. Portanto, "pessoa” confunde-se com soberania, uma caracterização plenamente política e biopolítica do ser humano. Essa identificação da pessoa com a soberania individual está na base da confusão com a categoria de autonomia, visão que levou água ao próprio moinho 
da deriva biológica, porque o dado corporal foi reduzido a instrumento de realização da pessoa. Assim, a categoria de pessoa, entendida como soberania e autonomia, proposta por Maritain, para opor-se à deriva biológica, contribuiu, ao contrário, para o fortalecimento do dispositivo da captura biopolítica (MARITAIN, 1967).

A lógica imunitária, que isenta o indivíduo dos encargos do comum, está, baseada nessa concepção biopolítica de pessoa como soberania e autonomia. Por isso, Esposito (2009), para superar as aporias do conceito de pessoa, propõe a categoria de impessoal como via alternativa para uma referência ética, contrapondo o pensamento de Simone Weil ao de Maritain, porque a filósofa analisa a pessoa a partir da sua dependência do coletivo e do Direito, onde ela busca proteção, encontrando somente exclusão e discriminação pelo uso da força que está na base do direito para salvaguardar privilégios. 0 problema, segundo a autora, está na definição das notas particulares que caracterizam a pessoa, requerida pelo Direito, para proteger determinada categoria de pessoas e excluir outras, o que instaura a dinâmica imunitária (WEIL, 2000).

Weil propõe, uma argumentação alternativa: se o conceito de pessoa serviu, historicamente, para criar discriminação entre os seres humanos, a solução é contrapor-lhe a forma inversa do impessoal. 0 pessoal é definido pela relação "eu-tu" que discrimina quem não é um alter ego; e o impessoal se refere ao "eles", que interrompe o mecanismo de exclusão. Weil não contrapõe o pessoal ao impessoal, mas afirma que o impessoal é um dispositivo, na pessoa, que impede a discriminação. Por isso afirma com ênfase que "o sagrado, longe de ser a pessoa, é aquilo que, no ser humano, é impessoal. Todo impessoal no ser humano é sagrado e tão somente ele" (WEIL, 2000, p 4).

Tendo como ponto de partida essa intuição de Weil, Esposito vai em busca de indícios em outros autores como Benveniste, Kojève, Jankelevitch, Levinas, Blanchot, Foucault e Deleuze para fundamentar o impessoal como antidoto para a lógica imunitária, já que essa se fundamenta no direito contratual dos indivíduos, entendidos como pessoa humana, detentores de direitos para se excluírem dos encargos do comum. A introdução do conceito de impessoal pode sustar esse mecanismo de isenção e de privilégio (ESPOSITO, 2009). 
Essa linha de reflexão pode servir de caminho para questionar a captura biopolítica negativa dos direitos humanos, exposta na primeira parte do artigo. Contudo, para tornar possível uma biopolítica positiva é necessário trazer para o debate a categoria de "comum' como complementar à categoria de impessoal para que os direitos humanos ativem a potência de vida. A lógica imunitária isenta do comum, baseada nos direitos da pessoa e é chancelada pelo Direito contratual. Para efetivar o impessoal, como o sagrado que verdadeiramente defende a pessoa, como defende Weil, é necessário recuperar a lógica do "comum", contrapondo-se ao mecanismo imunitário e permitindo ativar a potência de realização dos direitos. A concretização dos direitos humanos depende de mecanismos comuns, politicamente construídos, que potenciam a sua efetivação. Mas o que significa potência e como ela se relaciona com o comum?

Trata-se de uma potência que não passa ao ato, como pede a visão aristotélica, mas uma potência que sempre permanece como potência do não ou destituinte de qualquer obra que expresse a potência. Em outras palavras uma potência, como processo, que nunca se esgota num resultado. Para entender essa compreensão de potência é necessário, segundo Agamben, relacioná-la com o comum e a comunidade, "porque o fato de ser inerente a cada potência um princípio comunitário, é função do caráter necessariamente potencial de toda comunidade" (AGAMBEN, 2017, p. 237).

Em outras palavras é o comum que possibilita a potência em permanente processo destituinte de suas concretizações num ato/resultado, sendo necessário, no entanto, explicar o que se entende por comum. 0 comum não se identifica com o common da tradição anglo-saxã comunitarista, para a qual o comum se confunde com os dados identitários de pertença comunitária. Para essa concepção, trata-se de traços de identidade que são dados comuns a um grupo, como cultura, língua, costumes etc. 0 comum significa a redução ao uno que não aceita a diversidade. Sabe-se que essa compreensão cria discriminação e exclusão social para quem não apresenta os traços de pertença. A visão do comum, defendida aqui, não tem a ver com essa compreensão; ao contrário, se opõe, justamente a ela. Comum não é algo dado, não possui qualquer identidade ou essência prévia, mas uma dinâmica a ser construída agonísticamente 
no conflito. Em outras palavras, trata-se de dessubstancializar o comum. Nessa perspectiva, comum é a própria condição de potência para uma abertura contínua a toda riqueza possível e desejável que faça surgir uma comunidade, não caracterizada por particularidades identitárias, mas por processos antagonistas potencializadores do comum (MENDES, CAVA, 2017; DARDOT, LAVAL, 2017).

Traduzindo essa explicação para a visão de Esposito, trata-se de reconstituir a communitas, liberada da lógica imunitária que isenta dos encargos comuns, para uma comunidade permanentemente potencializadora de dinâmicas do comum (ESPOSITO, 2007).

A efetivação dos direitos humanos, pautada no indivíduo/pessoa, leva a uma compreensão dos direitos, como resultados obtidos e chancelados pelo direito, não abertos a novas compreensões e concretizações. Essa visão pode conduzir a dinâmicas imunitárias que isentam e criam privilégios em relação aos encargos do comum. 0 indivíduo defende-se do comum apoiado nos seus direitos. Ao contrário se a efetivação dos direitos se fundamenta no comum e está baseada no impessoal, os direitos se configuram, como potência, sempre aberta a novas compreensões, cuja concretização precisa ser gestada no conflito social e no embate político, construindo, continuamente, dispositivos comuns para sua execução. Os direitos humanos não são um resultado obtido, mas uma potência, como processo, sempre aberta a novas realizações que dependem, para sua efetivação, do comum. Assim, os dispositivos do comum e do impessoal permitem a universalização concreta dos direitos humanos, dificultando a introdução de dinâmicas imunitárias que isentam do comum e capturam os direitos humanos a serviço de interesses individuais contra o bem comum.

Retomando a linha de reflexão, pode-se dizer que a categoria do impessoal que se opõe à lógica imunitária das caracterizações de pessoa e a lógica do comum que instaura dinâmicas antagônicas potencializadoras de uma permanente constituição do viver em comum são as bases para uma efetivação dos direitos humanos num contexto de biopolítica. Elas oferecem ferramentas para uma desconstrução da captura biopolítica negativa dos direitos humanos pela lógica imunitária e para uma proposta de biopolítica positiva de transformar os direitos em potencializadores do comum. 


\section{CONCLUSÃO}

O modelo de bioética crítica tem os direitos humanos e a defesa da dignidade humana como referências éticas para avaliar situações conflitivas em que está implicada a vida. Essa perspectiva foi corroborada pela Declaração Universal de Bioética e Direitos humanos, emanada pela Unesco em 2005, depois de longas discussões e acordos entre as partes (UNESCO, 2005). A comissão que preparou o esboço da declaração que chegou ao plenário estava dividida entre o grupo que queria acentuar o paradigma da autonomia, centrado nos direitos individuais e focado nos usos das biotecnologias, que congregava os países ricos, capitaneados pelos Estados Unidos, e o grupo contrário, liderado por Brasil e Índia, que defendia o paradigma da vulnerabilidade, insistindo na inclusão de direitos sociais coletivos de proteção dos grupos e das populações vulneradas e de acesso aos bens necessários à saúde e à uma vida digna. Os embates demonstraram que existem dois paradigmas de bioética, um fundado na autonomia do indivíduo, defendendo para cada um a possibilidade de escolha; e o outro baseado em políticas comuns do coletivo para proteger indivíduos e grupos que padecem situações de vulneração humana e social. Esses dois paradigmas de compreensão dos direitos humanos estão presentes na Declaração, que é fruto de um consenso. Nesse sentido, pode-se dizer que ela também pode estar atravessada e ser usada pelas duas lógicas, uma imunitária, fundada na autonomia que isenta o indivíduo dos encargos do comum e a outra que potencializa a constituição de dinâmicas públicas comuns para a defesa e a efetivação dos direitos sociais. Por isso, é indispensável para a bioética o uso da ferramenta hermenêutica crítica para analisar as lógicas que movem a interpretação e efetivação dos direitos humanos. 


\section{REFERÊNCIAS}

AGAMBEN, Giorgio. 0 uso dos corpos (Homo Sacer IV, 2). São Paulo: Boitempo Editorial, 2017.

CHRISPINO, Álvaro. Introdução ao estudo das políticas públicas: uma visão interdisciplinar e contextualizada. Rio de Janeiro: FGV Editora, 2016.

DARDOT, Pierre; LAVAL, Christian. Comum: ensaio sobre a revolução no século XXI. São Paulo: Boitempo, 2017.

ESPOSITO, Roberto. Immunitas: protección y negación de la vida. Buenos Aires: Ed. Amorrortu, 2005.

Bios: biopolítica y filosofía. Buenos Aires: Ed. Amorrortu, 2006.

Communitas: origen y destino de la comunidad. Buenos Aires: Ed. Amorrortu, 2007.

Tercera persona. Politica de la vida y Filosofía de lo impersonal. Buenos Aires: Ed. Amorrortu, 2009.

FIGUEIREDO, Mariana Filchtiner. Direito fundamental à saúde: parâmetros para sua eficácia e efetividade. Porto Alegre: Editora do Advogado, 2007.

FOUCAULT Michel. História da Sexualidade I: a vontade de saber. Rio de Janeiro: Ed. Graal, 1977.

As palavras e as coisas. São Paulo: Martins Fontes, 1999.

Nascimento da Biopolítica. São Paulo: Martins Fontes 2008.

JUNGES, José Roque. Direito à Saúde, Biopoder e Bioética. Interface - Comunic., Saúde, Educ., v.13, n.29, p. 285-295, abr./jun. 2009.

KOTTOW, Miguel. Bioética de proteção: considerações sobre o contexto latinoamericano. In: SCHRAMM Roland Fermin; REGO, Sérgio; BRAZ, Marilene; PALACIOS Marisa. (Orgs.) Bioética: riscos e proteção. Rio de Janeiro: Ed. UFRJ / Fiocruz, p. 29-44, 2005. 
KOTTOW, Miguel. Ética de protección: una propuesta de protección Bioética. Bogotá: Ed. Universidad Nacional de Colombia, 2009.

MARITAIN Jacques. Os direitos humanos. São Paulo: Ed. José Olympio, 1967.

MENDES, Alexandre; CAVA, Bruno. A constituição do comum. Antagonismo, produção de subjetividade e crise no capitalismo. Rio de Janeiro: Ed. Revan, 2017.

SARLET, Ingo Wolfgang; SAAVEDRA, Giovanni Agostini. Judicialização, reserva do possível e compliance na área da Saúde. Revista de Direitos e Garantias Fundamentais, Vitória, v. 18, n. 1, p. 257-282, jan./abr: 2017.

SCHRAMM, Roland Fermin. A bioética de proteção em saúde pública. In: FORTES, Paulo Antônio de Carvalho; ZOBOLI, Elma Lourdes Campos Pavone (Orgs.). Bioética e Saúde Pública. São Paulo: Ed. Loyola, 2003. p. 71-84.

SCHRAMM, Roland Fermin Bioética sem universalidade? Justificação de uma bioética latino-americana e caribenha de proteção. In: GARRAFA Volnei; KOTTOW, Miguel \& SAADA Alya. Bases conceituais da bioética: enfoque latinoamericano. São Paulo: Ed. Gaia, 2006. p. 143-157.

SCHRAMM, Roland Fermin; KOTTOW, Miguel. Principios bioéticos en salud pública: limitaciones y propuestas. Cadernos de Saúde Pública, Rio de Janeiro, v. 17, n. 4, p. 949-956, jul./ago., 2001.

UNESCO, Declaração Universal de Bioética e Direitos Humanos, 2005. Disponível em: http://unesdoc.unesco.org/images/0014/001461/146180por.pdf

WEIL, Simone. "La persona y lo sagrado". In: Escritos de Londres y últimas cartas (1942). Madrid: Editorial Trotta, 2000. Disponível em: https://lahesiquia. files.wordpress.com/2011/02/weil-simone-la-persona-y-lo-sagrado.pdf. Acesso em: 19 ja. 2018.

Recebido em: 3-11-2017

Aprovado em: 29-1-2018 


\section{José Roque Junges}

Doutor em Teologia Moral pela Pontificia Università Gregoriana de Roma, Itália; mestre em Teologia pela Pontificia Universidad Católica de Chile; especialização em História do Brasil Contemporâneo pela Universidade do Vale do Rio dos Sinos - UNISINOS; graduação em Filosofia pela Pontifícia Universidade Católica do Rio Grande do Sul; atualmente é professor de bioética nos cursos de graduação da área de saúde; professor/pesquisador do PPG em Saúde Coletiva da UNISINOS; coordenador do Comitê de Ética em Pesquisa (CEP) da UNISINOS; líder do grupo de pesquisa CNPq "Bioética e Saúde Coletiva”; editor associado da Revista Brasileira de Bioética (RBB); bolsista de Produtividade Científica do CNPq. Email: roquejunges@hotmail.com.

Universidade do Vale do Rio dos Sinos (UNISINOS)

Av. Unisinos, 950 - Cristo Rei, São Leopoldo - RS, 93020-190 